\title{
Towards a Smart Community Centre: SEIDET Digital Village
}

\author{
Jackie Phahlamohlaka, Zama Dlamini, Thami Mnisi, Thulani Mashiane, \\ and Linda Malinga \\ Council for Scientific and Industrial Research (CSIR) \\ Pretoria, South Africa \\ \{JPhahlamohlaka, IDlamini, TMnisi1, TMashiane, LMalinga\} @csir.co.za
}

\begin{abstract}
South African communities are constantly being developed through new ICT projects which are initiated by individuals, government and private organisations. The problem with these developments is that they are implemented in isolation. This isolation causes limited sharing of resources, duplication, poor-governance of the resources and in worse-case scenarios, failure of project initiatives. This paper proposes a model that could be used to address these problems by focusing on the SEIDET community centre using it as an example. The model follows a descriptive analysis of ICT related work spanning over two decades performed within the SEIDET context, including the ongoing SEIDET Digital Village. The benefits of the proposed smart community centre model include community and rural development through sharing of scarce ICT resources. It could further provide support for entrepreneurs through training interventions, action-based research for policy development as well as spawn local innovation and free-sharing of resources and services.
\end{abstract}

Keywords: Community Centre, Digital Village, SEIDET, Siyabuswa, Smart Community Centre, Village Operators.

\section{Introduction and Background}

The question as to whether the Siyabuswa Educational Improvement and Development Trust (SEIDET) was like Linux was raised in 2003 by Tom Siebeling [1]. Broadly speaking, Linux is associated with open source and innovation. SEIDET is also an organisation that encourages the collaboration of individuals in order to achieve the common goal of uplifting the community of Siyabuswa. With these characteristics of being open and innovative in its outlook, a question as to whether it could successfully morph into a Smart community centre within the envisaged SEIDET Digital Village could be asked. Smart community centre concept could be defined by looking at the smart city definitions.

According to Caragliu, Belbou and Nijkamp (2009), a city can be referred to as 'smart' when investments in human and social capital, traditional and modern Information and Communication Technologies (ICT) communication infrastructure fuel sustainable economic development and a high quality of life, with better management 
of natural resources, through participatory action and engagement [2]. Chourabi et al. (2012) believe that a smart city concept essentially means efficiency [3], but efficiency based on the intelligent management and integrated ICTs, and active citizen participation, resulting in a new kind of governance and genuine citizen involvement in public policy [3].

From the above definitions, the notion of 'smart' of ICT infrastructure, education, learning, social and human capital development and innovation is emphasised. With an emerging drive by the SEIDET board towards ICT enabled entrepreneurship, the authors were curious to investigate how the Smart Community Centre idea would be pursued within the envisaged Digital Village. The authors were also aware of studies currently undertaken within the Council for Scientific and Industrial Research (CSIR) in South Africa and globally on Smart Cities and wanted to explore possibilities for collaboration between SEIDET and the CSIR on research, development and innovation. Since the definition of 'smart' has as its core, access to and use of ICT infrastructure, a short background on ICT related work at SEIDET is in order.

This paper is part of a long term project made up of three phases as illustrated in Figure 1. It focuses on the first phase of the project and it aims to formulate a smart community centre model as well as analyse it in SEIDET community centre context. This is achieved by conducting a literature study on SEDEIT community centre, smart city and smart community.

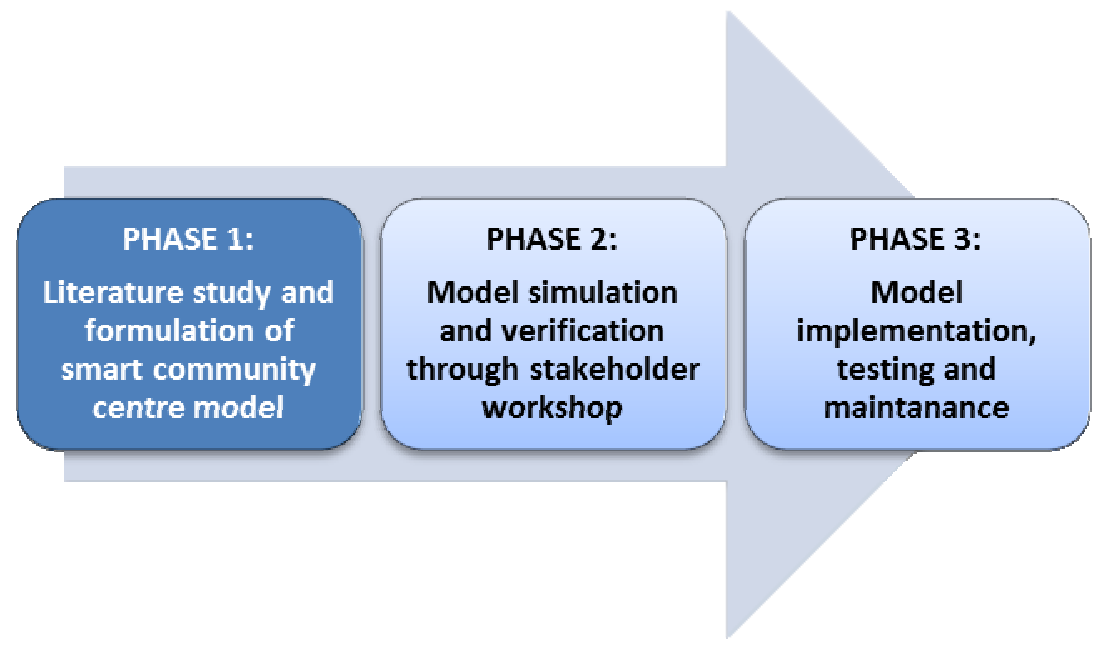

Fig. 1. Smart Community Centre Model Plan

The rest of the paper is organised as follows: Section 2 presents the background on elements of the ICT enabled entrepreneurial drive contextualised within SEIDET is outlined and a literature study on smart cities and smart communities is undertaken; the proposed model that SEIDET could consider as it moves towards becoming a smart community centre is presented in Section 3. The paper concludes in Section 4 
with a discussion on analysis which further motivates for the innovative collaboration between SEIDET and the CSIR.

\section{$2 \quad$ Literature Study}

\subsection{SEIDET Community Centre}

Siyabuswa Educational Improvement and Development Trust (SEIDET) is a nonprofit organization, initiated in May 1990 by the Siyabuswa community located in Mpumalanga province of South Africa. This is a community centre consisting of two ICT labs, readily available to the community under strict administration. This community centre hosts various community based projects. These projects include educational and business oriented initiatives. The goal of these projects is to involve various stakeholders in the public sector, the private sector as well as the general community participation in educational and economic development [4].

ICT related work and studies at SEIDET are well documented, and span more than a decade and a half [4,5]. Pioneering work was done by a number of academics from the Department of Informatics at the University of Pretoria [5]. Several conference proceedings, journal publications and a book dedicated to this work are readily available [5].

Two Masters dissertations and five PhD theses were completed using some aspects of ICT related work at SEIDET [5]. None of these studies were about the establishment of a smart community centre. Rather, they were about how ICT could contribute to socio-economic development. Since the concept of "smart" assumes ICT infrastructure access and use, all these studies are useful references for purposes of this paper [6].

The SEIDET project has helped expose members of the Siyabuswa community to basic ICT skills. Many leading professionals from both local and provincial governments in the Mpumalanga Province of South Africa touched a computer keyboard for the first time at the SEIDET community centre in Siyabuswa. Hundreds of community members and thousands of school learners as well as all primary school science teachers from Nkangala Region of Mpumalanga province were exposed to basic ICT literacy and learnt how ICT could be used to support them in their learning and teaching tasks at SEIDET [4]. This makes the SEIDET community centre a profound-ideal community centre for this project to use in testing the proposed smart community centre model.

In recognition of the ground breaking work done in partnership with the University of Pretoria on ICT use at SEIDET, a national seminar leading to the launch of the National eSkills Plan of the Department of Communications (DoC), was co-hosted by SEIDET in Siyabuswa. The following quote from DoC press release in 2009 succinctly captures the recognition:

"It is fitting that this first iJima be located in Siyabuswa, the site of SEIDET and the location of a partnership with the University of Pretoria including more than fifteen years of community focused research on ICT enabled socio-economic development" (Department of Communications, RSA, 2009) [7]. 
All of the above sited background presents the SEIDET community centre as a well-established environment with great potential of becoming a modern state-of-art ICT community centre; overcoming most of the day-to-day ICT challenges through ICT utilisation, especially distracted governance, decentralisation of resources which often result in limited sharing of skills, knowledge, services and resources. This paper proposes a model that could be used to overcome these challenges using smart community centre concepts.

There are a number of ICT initiatives that are taking place at the SEIDET community centre. Some of these initiatives involve the South African government, Mpumalanga province municipalities, public and private sector, academic and research institutions (such as University of Pretoria and CSIR) who currently are working with SEIDET on research and community development. These isolated collaborations can be better managed using the existing ICT resources and infrastructure, such that SEIDET community centre houses the centralised system that manages both the service providers and the consumers. Having such system in place could also reduce redundancy of service delivery. The current ICT initiatives at SEIDET community centre, working together with University of Pretoria (UP) and CSIR include, the eentrepreneurial training and eSkills programme, Cybersecurity awareness training and CSIR broadband for all (BB4All) and village operators project [4], [7,8]. All these initiatives are discussed in details in the following subsections.

\section{E-entrepreneurship Training and eSkills Programme}

The first entrepreneurship training of sixteen members from the SEIDET Community was done in 2011 by the Department of Economics at UP. This was followed by further training of fourteen members from the broader Siyabuswa Community in 2013 at the SEIDET community centre in Siyabuswa. On the part of the Board of SEIDET side, the training was in line with one of its objectives, to enable communities to participate in economic development [5].

Linked to this entrepreneurship training was also the eSkills training component, facilitated once again by academics from the Department of Informatics, UP. The second training at the SEIDET community centre in Siyabuswa was the collaboration between SEIDET, the University of Pretoria and the CSIR; with the CSIR focusing on Cybersecurity Awareness Training [4], [9,10]. The eSkills component was conducted as part of the broader eSkills Programme of the Department of Communications mentioned earlier in the introduction. The combination of the entrepreneurship and the eSkills training was dubbed e-entrepreneurship training.

The SEIDET Digital Village concept referred to in this paper is an outcome of the e-entrepreneurship training programme [4]. It is conceptualised as a variant of the SEIDET Model which focuses on enabling communities and individuals to participate in economic development. It is envisaged that the conversion of the SEIDET community centre to a Smart community centre will be pursued.

\section{Cybersecurity Awareness Training}

In an effort to prevent innocent internet users from becoming victims of cyber-attacks, the CSIR has initiated an intensive cyber security awareness program developed specifically to educate novice internet and technology users with regard to basic cyber 
security. As part of the e-entrepreneurship training initiative, the entrepreneurs were trained on the safe and secure online behaviour to ensure their safety if they were to consider using the Internet to either market or sell their products. They were further given a better view of the vulnerabilities that comes with the advantages of the Internet [10].

The topics that were covered in the training session include: Cybersecurity in the Enterprise, Physical Computer Security, Mobile Security, Password Protection, Malware, Pop-ups - Adware and Spyware, Botnets, Surfing the web, Email Security, File Sharing and copyright, Internet Banking, Cookies, Phishing Attack Avoidance, Social Networking, Social Engineering, Identity Theft and Cyberbullying [8]. This is a significant aspect of any ICT training for any user as it encourages safe use and good behaviour when using the internet. It further provide list of threats and best practises when using the technological devices. This training initiative is regarded as an important aspect of the smart user services on the proposed model, because it promotes safe use of any technology as how one safe guard their lives in real life.

\section{CSIR BB4All and Village Operators Project}

Broadband for All (BB4All) is the outcome of a collaborative effort led by the CSIR's Meraka Institute to bridge the digital divide and bring the social and economic benefits offered by broadband connectivity to rural communities (such as Siyabuswa) in South Africa and other developing countries [11]. The objective of the project is to offer broadband access to rural communities in an affordable and sustainable fashion. This is made possible by enabling low cost building and sharing of connectivity through utilising Mesh Networking [12] principles and equipment to expand coverage within local communities negating the need for expensive radio equipment and high radio towers.

To ensure sustainability of the initiative, the local community and more specifically adequately skilled and trained local entrepreneur also known as the Village Operators (VO) are responsible for operating, promoting and expanding the BB4All offering within Siyabuswa [11]. SEIDET facilitated the VOs recruitments via schools and the Mpumalanga department of Education. SEIDET is regarded as a significant stakeholder and key contributor to the BB4All initiative. They are local entrepreneurs; young people with the right attitude and approach to become VOs. The VOs undergo entrepreneurial and business mentoring, personal development and training on the BB4All network infrastructure maintenance, operation and support [13].

The function of the VO is to service an exclusive area with limited number of clients, key clients being clusters of schools. The clients are connected through a peerto-peer community mesh network. The mesh community networks are linked through a backhaul network called backhaul mesh. In addition to connecting the mesh communities, this mesh network contains a link to an IP backbone for IP services and Internet (See Figure 2). For redundant routing, this type of network ensures that a VO's device can link to two or more other VOs from other communities. 


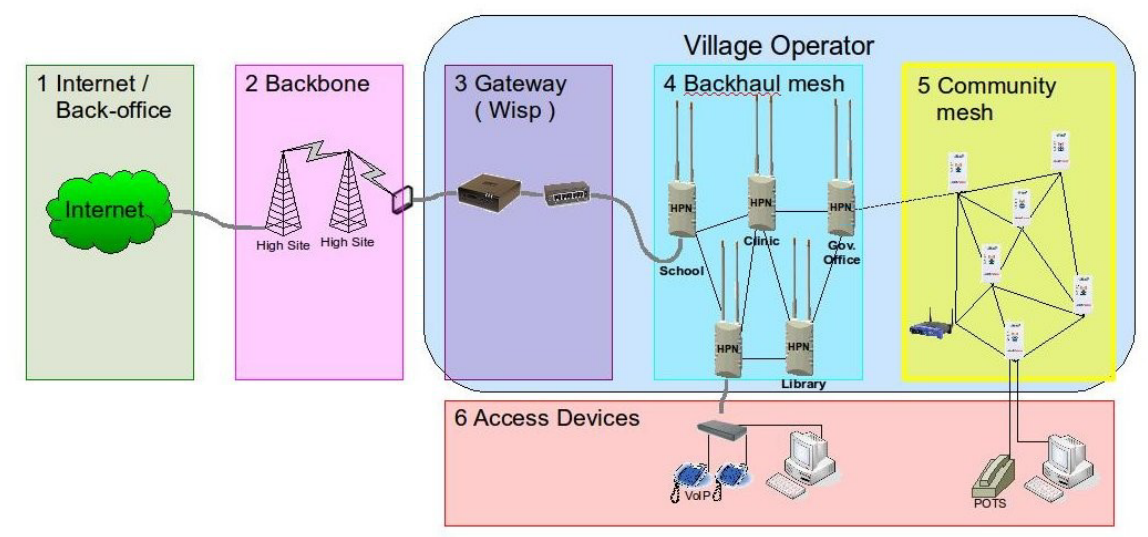

Fig. 2. CSIR BB4All Network Infrastructure [13]

The three initiatives discussed above could better be managed and distributed using governed technological advances that could be encompassed within the concept of a smart city. The smart community centre concept is based on the smart city concept; therefore the following subsections present literature on smart city and smart community.

\subsection{Smart City}

The concept of 'smart city' has become popular across the world and is currently the centre of attention for industry and governments globally [14,15]. Scholars and domain experts have presented ideas in an effort to describe smart cities; some of the definitions are presented as follows:

- Partridge (2004) believes that a smart city is "a city where the ICT strengthen the freedom of speech and the availability of public information and services" [16].

- Bowerman (2000) described a smart city as "a city that monitors and integrates conditions of all of its critical infrastructures, including roads, bridges tunnels, rails, subways, airports, seaports communications, water, power, even major buildings can better optimize its resources, plan its preventive maintenance activities, and monitor security aspects while maximizing services to its citizens" [17].

- Caragliu et al (2009) defined the smart city concept as "a concept to enable management and governance of the resources of the city through ICT, social, intellectual and the environment to create sustainability and efficiency by information sharing" [2].

- Kehoe et al (2011) consider a smart city as a city that "makes optimal use of all the interconnected information available today to better understand and control its operations and optimize the use of limited resources" [18].

- Rios (2012) defined a smart city as "a city that gives inspiration, shares culture, knowledge, and life, a city that motivates its inhabitants to create and flourish in their own lives" [19]. 
From the above definitions of a smart city, the common components of a smart city can be identified as people, technology and governance. These can be regarded as the drivers to achieve a smart city $[14,15]$ and are discussed in detail below.

\section{Smart People}

The people, who are part of a smart city, comprise of any individual or organisation that has an interest in the success of the smart city. For example entrepreneurs, education institutions and law enforcement institutes, government institutes, NGOs as well as volunteers. The people who are active in a smart city are referred to as smart people [3], [19,20,21]. Smart people need to be properly educated and trained to operate in the smart city [15]. Once qualified, they are able to use their creativity in leveraging the city's infrastructure in order to create social, economic and environmental values. Smart people must be committed to a lifelong learning, and sharing of knowledge [15], [18]. These characteristics of smart people enable them to create a sustainable smart economy, smart environment and smart education system and an overall smart living [15], [18,19].

\section{Smart Technology}

An important aspect of a smart city is the platform that allows the interaction between the smart people. This platform is referred to as, the technology of the city. Technology in a smart city includes all the infrastructure, ICT, applications, smart technologies, digital networks and mobile devices $[17,18]$. These technologies are used as a channel or platform where smart people share knowledge, skills and services. The technology is leveraged in order to maximise the value to smart people [2]. For example, a smart person can use a smart device such as a cellular telephone to plan their route from a publicly accessible traffic web portal or an electronic board. This electronic traffic management, amongst other benefits, enables goods to be delivered on time, which increases productivity rate of the city.

\section{Smart Governance}

The interaction of the smart people amongst themselves, as well as the interaction with the technology needs to be governed [15]. Governance is the cornerstone of smart cities. This includes policies, regulations and directives that encourage collaboration, partnership and participation within the smart city. Governance ensures that the actors within the smart city act in a predictable and monitored manner. Governance oversees the standardisation of how different stakeholders interact within the smart city [16], [18], [20].

By synergising the components of a smart city, the goal of a smart city is realised and the people of the city fully harness the resources that their city provides [15], [20]. Examples of this harnessing can be seen in processes such as information gathering, where a city deploys an energy smart grid to monitor and manage the energy usage. This is achieved by interconnecting energy measuring sensors in predetermined locations through ICTs. These sensors send data to a central system. This data can be used for future energy resource planning [22]. Service delivery can be greatly improved by connecting government, public and private services through ICT. Emergency service personnel can be equipped with a smart device which has Internet 
access. The device can also be used to access a health record of a patient remotely from a public health record database [20]. This leads to accurate and fast treatment of the patient at the scene. Safety and Security can also be improved by inter-connecting smart devices such as cameras and motion sensors through ICT [23]. Some of the early studies on smart cities have been initiated by the CSIR Meraka Institute [24,25].

The concept of smart city focuses on a broader view of development of a city through ICT. This study focuses on the development of the smart community centre model using SEIDET community centre as the test-bed, yet flexible enough to be adapted to any South African community. The following subsection presents the concept of smart communities.

\subsection{Smart Community}

The phrase: "No man is an island", is the first line and the title of the popular poem by John Donne [26]. This line stresses that people need each other to survive. For this reason, in all parts of the world, people live in communities. A community can be defined as either a group of individuals and organisations who share an environment or a group of individuals and organisations that share common values or goals $[27,28,29]$.

The pervasiveness of the Internet has made it possible for new types of communities to be formed. Technologies, such as, blogs have created a platform for people with common interest to share information and experiences with each other [30]. This notion of using the Internet to work together toward a common goal is the foundation of smart communities [6].

A smart community is a group of individuals and organisations that work together to leverage Information Technology (IT) in the creation of economic, cultural and social value [6]. Smart community members can include individuals, educational, government and business organisations [6]. A smart community can be seen as group of 'smart people' as defined in Section 2.2. In other words, a smart community is a system where people and organisations use IT to enhance the way that they conduct their everyday business. This enhancement can lead to advantages, such as, new revenue streams or attaining new knowledge that can be used to improve the efficiency of a business functions [6], [22].

Smart communities can exist in the virtual space, such as in SecondLife [31] or a hybrid of physical and virtual space, such as, Silicon Valley [32]. On the SecondLife platform, people leverage the Internet to perform business transactions, lecture presentations and even social gatherings. In both domains members of the community build relationships with each other for specific purposes such as collaborative learning, information and resource sharing [31]. Simply providing IT capability to a community does not make it a smart community. The individuals and organisations within the community must be educated and trained to make the applications more accessible and useful to them. It is only when the members of the community can use IT capabilities to produce new values that improve their lives, can it be classified as a smart community [6]. 
The availability of technology in a smart community is also as important as it is in a smart city. The infrastructure acts as a platform where community members interact. The networking infrastructure of the smart community can be made up of different technologies that need to interact with each other. Like most networking projects, the interoperability of different technologies is a challenge. This is because different technologies use different protocols and standards [6].

Smart communities have the potential of speeding up the processes of innovation and getting a product or service to the market. This is because members of the community work in partnership to realise specific goals. The digital divide can also pose as a threat in smart communities. Partnerships such as these can help in closing this divide [9]. By pulling resources together, members of the community can buy and maintain IT capability that would not have been attainable individually. Some members of the community may not have enough knowledge of the technology to be able to leverage it. Lack of knowledge and understanding of potential benefit for the members may lead to slow or no 'buy in' by the community [5]. This threat can be mitigated through continuous training and support to all the members of the community that need it. Community members must be consulted for input throughout the development and implementation in order to increase their desire to be a part of the smart community.

The literature of the ICT enabled entrepreneurial drives, all of which are linked to SEIDET community centre; and having looked at the literature on Smart Cities and Smart Communities; the following section presents the proposed Smart Community Centre model.

\section{The Proposed Model of a Smart Community Centre}

This section presents the proposed smart community centre model in the SEIDET community centre context. Some of the components of the model are derived from the above literature. The model aims to overcome the challenges of decentralised services and resources which results in limited sharing, redundancy of service delivery, and difficult access of services. The following subsections present the proposed model in details as well as an example of how it could be applied in the SEIDET context.

\subsection{Smart Community Centre Model}

As defined in the introduction and background Section 1, some of the challenges that the community of Siyabuswa is facing are; having disjointed developments in place which often result in poor administration, miscommunication and limited sharing of facilities and resources. These challenges are also experienced at the SEIDET community centre.

The proposed model, depicted in Figure 3, is a smart community centre model which aims to resolve some of these challenges. These include distributed resources, lack of governance, collaboration and sharing. This is achieved by employing smart city concepts to the existing SEIDET ICT architecture. 


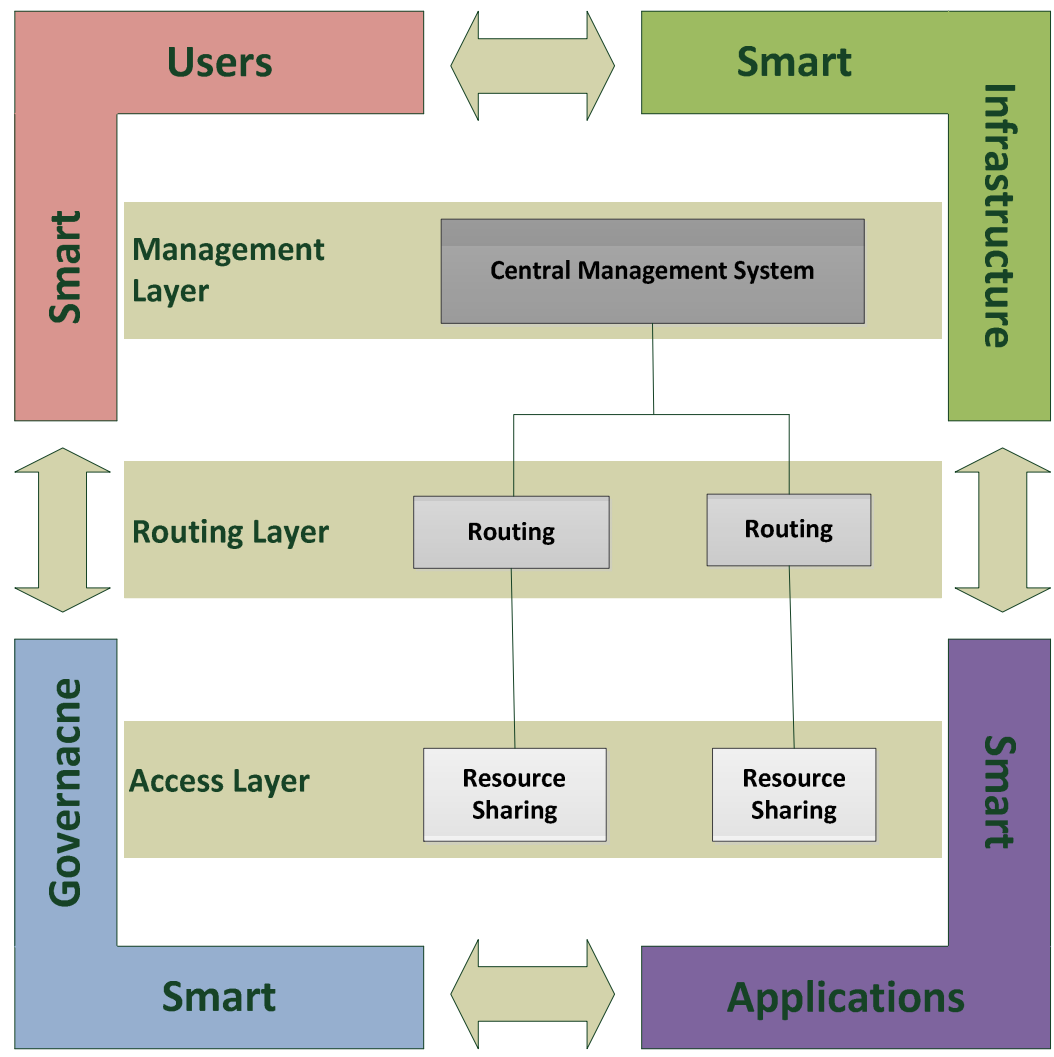

Fig. 3. Proposed Smart Community Centre Model

\section{Smart Community Centre Services}

The proposed model is based on a service oriented approach. From the definition of smart city, it was identified that the value is provided by the services that are delivered by the components (people, technology and governance); hence, the service oriented approach. It focuses on services required to achieve the goal of the smart community centre. These services are; smart users, smart infrastructure and ICT, smart applications and smart governance.

The services are discussed in detail below.

- Smart Users: These services are skills and knowledge based provided by the smart community centre such as education and training. These services empower the users with the skills to participate, and share resources. Examples of smart users within a smart community centre context include: training of users to able to efficiently utilize both smart applications and smart infrastructure to their benefits and the benefits of their businesses. This further improves quality of life and improved the economy, which can be summed as "smart living and smart economy". This will develop further participation in public life, flexibility, creativity/ innovativeness, social and cultural plurality and affinity to lifelong learning. 
- Smart Infrastructure and ICT: These services are network and ICT based and provide two functions. The first function is to create an information flow path. For an example, implementation of networks, such as the mesh (BB4All), allow information to flow. The second function is to provide access to the network through smart devices. For an example using tablets, servers, etc. Other examples of these services include; information systems (applications and data architecture), technological infrastructure, business architecture and communication protocol.

- Smart Applications: These are services that are provided by interactive software packages. These includes web portal in the remote servers, applications in the users' devices. For an example, in resource management, they enable visualisation of the resources and registration.

- Smart Governance: These are services that are provided by the stakeholders; public, private sector in a form of policies, rules and regulations for participation. These services aim to promote a system with predictable behaviour as participants are obliged to follow them. These rules, regulations, policies are formulated through active reviews, and inputs from all stakeholders. The main role for the smart governance is to promote participation and decision making in the smart community centre.

\section{Smart Community Centre Implementation Layers}

There are three layers in the smart community centre model and are shown in Figure

3 . These layers are components which provide different services at different levels in a resource management process. These layers are described in detail below:

- Access Layer: This is the user layer responsible for access to the system. It consists of the users and devices (as data resources providers and consumers) of the traditional community centre. The main role of this layer is to enhance sharing amongst the user and also supply information about resources and available services between the users and the routing layer.

- Routing Layer: This layer is responsible for the routing of requests between the entities (users and CMS) in the system. All data shared by users is interconnected, structured, sorted, processed and routed to and from both the access and management layer.

- Management Layer: This layer is responsible for central managing of the resources. It is the layer where all the data (shared services, application, software, etc.) is stored and managed for efficient utilisation intelligent decision making, better service monitoring and easy access of services.

\subsection{An Example of the Proposed Model Application within SEIDET Community Centre}

In subsection 2.1, the challenges that are faced by the Siyabuswa community, such as decentralisation of resource management, limited sharing and collaboration, and lack of governance of ICT resources were outlined. The smart community centre model is proposed to address these challenges. This subsection illustrates how the proposed model could be used in addressing some of these challenges through ICT. 
The entrepreneurs in Siyabuswa operate in isolation and as a result there is limited or no collaboration. Resources such as printers and fax machines are shared in a traditional manner, that is, if different entrepreneurs share a building, they will know the available resources by talking to each other. This model attempts to address such problems using modern means through ICT. This implies that exposing resources to participants in the smart community model system.

\section{Possible Smart Community Centre Services at SEIDET}

- Smart User: The smart user services could be all the human capital development services that are already provided at SEIDET community centre, such eentrepreneurship and eSkills programme and cybersecurity awareness training.

- Smart Infrastructure: The smart infrastructure and ICT services could be the network services that are already provided by the current BB4All network infrastructure which is available to SEIDET community centre.

- Smart Application: Currently, SEIDET does not have elements that can provide smart applications services.

- Smart Governance: The SEIDET stakeholders can provide the smart governance services after they have acquired the appropriate training.

\section{Registration Process}

The first process in the system is the registration process. In this process, users register with the central management system. The central management system keeps records of all VOs, resources and users. The smart governance services provide rules and qualification criteria to determine the fitness of the user. This includes the skills the user needs to actively participate in the system, in which such service are provide by the smart user services of the model. Upon successful registration, the user is given terms and conditions regarding participation, also provided by the smart governance.

\section{Resource Sharing}

Once the user has been registered in the system, they can start sharing and requesting resources. This process is divided into three layers: access, routing, management. Figure 3 shows an architectural implementation of the model for Siyabuswa.

- Access Layer: In the case of the Siyabuswa, a user uses a smart device (smart infrastructure and ICT), PC to log on with their credentials. Upon successful logon, a request is sent to the local VO, i.e. VO responsible for the area where the user is in. A user is any entity or participant that is capable of exposing and sharing resources. In the context of the SEIDET community centre, these could include the entrepreneurs, users, stakeholders, communication devices or sensors.

- Routing Layer: VOs play a pivotal role in this layer. VOs service an exclusive area. For example, assume that one entrepreneur attended an overseas training and would like to share business marketing ideas he learnt from that training in a form of a document. He will have to registers with the VO leader, the local VO keeps records of all shared resources from that area and has the responsibility make the resources available to all the community by uploading them to the central management system. 
VOs accept the requests from, and forward responses to the access layer. They keep track of the local resources. If a requested resource is not available locally, they route the request to the CMS. In the SEIDET context, an entrepreneur who needs a specific service submits their request and has it dealt with by the area specific VO. That VO responds to the inquiry. If the requested services are not available locally, the VO asks other VOs through a central management layer.

- Management Layer: All VOs and resources are registered with the CMS. The CMS accepts request from the VOs, query its database for the requested resource and responds to the VO.

This example illustrates how the proposed model could be adapted for the current SEIDET community centre towards making it a smart community centre. It goes through each of the services of the model and recommends the available SEIDET components that can fulfil the services of the model.

\section{Concluding Discussion}

SEIDET has made a big impact during the past decades of its existence, not only in terms of its contribution to human capital development through education, but also on how ICT could be accessed and used by communities in support of socio-economic development. The new thinking and drive by its board to morph it towards a Smart Community Centre within what they envision as the SEIDET smart community centre makes perfect sense. It could draw on a wide range of its previous collaborators, the CSIR included, to make this happen.

The Smart Community Centre model proposed in this paper follows a conceptual analysis of its ongoing open characteristics highlighted in the introduction. The ICT enabled initiatives discussed in section 2.1 are classic demonstrations of this facilitative and open nature of SEIDET. The proposed model encapsulates and borrows the concept of a Village Operator, developed by the CSIR as part of its BB4All project and identifies the currently available ICT enabled initiatives as the examples of the smart community centre services.

The central management system in the proposed model could be the anchor point of the envisaged SEIDET smart community centre, where members of the smart community, including the entrepreneurs, users and other organisations could be linked. Linked to the smart community centre could therefore be physical, virtual as well as communities of interest, such as researchers at the CSIR. For instance, several entities within the CSIR are already collaborating to look at a smart city model that could be fitting to the South African context. As part of this study, it could link up into the proposed smart community centre to experiment with some of the initial ideas. The smart community centre model proposed in this study could thus assist in attaching local meaning to the smart city model that the international community is interested in pursuing. 


\section{References}

1. Siebeling, T., Romijn, H.: Why People Contribute Voluntarily to Innovation: Insights from South Africa's Siyabuswa Educational Improvement \& Development Trust. In: Eindhoven Center for Innovation Studies (ECIS) (2005)

2. Caragliu, A., Del Bo, C., Nijkamp, P.: Smart cities in Europe (2009), http://ideas.repec.org/p/dgr/vuarem/2009-48.html

3. Chourabi, H., Nam, T., Walker, S., Gil-Garcia, J.R., Mellouli, S., Nahon, K., Pardo, T.A., Scholl, H.J.: Understanding smart cities: An integrative framework. Presented at the 2012 45th Hawaii International Conference on System Science (HICSS), pp. 2289-2297 (2012)

4. SEIDET, "SEIDET" (2014), http: / / www. seidet.org.za/ (last accessed on March 31, 2014)

5. Phahlamohlaka, J.: Community-driven projects: reflections on a success story: a case study of science education and information technology in South Africa. Van Schaik Publishers (2008)

6. Baskin, C., Barker, M., Woods, P.: Towards a smart community: Rethinking the strategic use of ICTs in teaching and learning. Aust. J. Educ. Technol. 19(2), 192-210 (2003)

7. Department of Communication-South Africa, E-Skills Institute newsletter (February 11, 2013), http: / /www.esi-sa.org/media-and-publications/pdfs / edition11_newsletter.pdf (accessed March 12, 2014)

8. Stillman, L., Herselman, M., Marais, M., Boshomane, M.P., Plantinga, P., Walton, S.: Digital doorway: social-technical innovation for high-needs communities. Electron. J. Inf. Syst. Dev. Ctries. 50 (2011)

9. Kaplan, A.M., Haenlein, M.: The fairyland of Second Life: Virtual social worlds and how to use them. Bus. Horiz. 52(6), 563-572 (2009)

10. Roux, R.: Broadband for all (BB4all) TM. CSIR Sci. Scope Mag. 3(3), 16-17 (2009)

11. Siebeling, T., Romijn, H.: How SEIDET achieved success-an exploration from the perspective of innovation theory. In: Phahlamohlaka, J., Braun, M., Romijn Roose, H. (eds.) Community-Driven Proj. Reflect. Success Story Case Study Sci. Educ. Inf. Technol. South Afr., p. 77 (2008)

12. Siebeling, T., Romijn, H.: A novel approach to innovation processes in community driven projects: how an extented learning selection model explains the success of SEIDET, an educational community development project in rural South Africa (2004)

13. Grobler, M., Dlamini, Z., Ngobeni, S., Labuschagne, A.: Towards a cyber security aware rural community (2011)

14. Dlamini, Z., Modise, M.: Cyber Security Awareness Initiatives in South Africa: A Synergy Approach. Case Stud. Inf. Warf. Secur. Res. Teach. Stud., p. 1 (2013)

15. Al-Hader, M., Rodzi, A., Sharif, A.R., Ahmad, N.: Smart city components architecture. Presented at the International Conference on Computational Intelligence, Modelling and Simulation, CSSim 2009, pp. 93-97 (2009)

16. Hollands, R.G.: Will the real smart city please stand up? Intelligent, progressive or entrepreneurial? City 12(3), 303-320 (2008)

17. Partridge, H.L.: Developing a human perspective to the digital divide in the'smart city (2004)

18. Bowerman, B., Braverman, J., Taylor, J., Todosow, H., Von Wimmersperg, U.: The vision of a smart city. Presented at the 2nd International Life Extension Technology Workshop, Paris (2000) 
19. Kehoe, M., Cosgrove, M., Gennaro, S., Harrison, C., Harthoorn, W., Hogan, J., Meegan, J., Nesbitt, P., Peters, C.: Smarter cities series: A foundation for understanding ibm smarter cities. Redguides Bus. Lead. IBM (2011)

20. Rios, P.: Creating 'The Smart City' (2012)

21. Nam, T., Pardo, T.A.: Conceptualizing smart city with dimensions of technology, people, and institutions. Presented at the Proceedings of the 12th Annual International Digital Government Research Conference: Digital Government Innovation in Challenging Times, pp. 282-291 (2011)

22. Su, K., Li, J., Fu, H.: Smart city and the applications. Presented at the 2011 International Conference on Electronics, Communications and Control (ICECC), pp. 1028-1031 (2011)

23. Kenichi, M.: Information and Communication Technology and Electric Vehicles-Paving the Way towards a Smart Community. IEICE Trans. Commun. 95(6), 1902-1910 (2012)

24. Li, X., Lu, R., Liang, X., Shen, X., Chen, J., Lin, X.: Smart community: an internet of things application. Commun. Mag. IEEE 49(11), 68-75 (2011)

25. Donne, J., Berkeley, C.: No man is an island. Peacock Press (1964)

26. Stevenson, A.: Oxford dictionary of English. Oxford University Press (2010)

27. Rifkin, S.B., Muller, F., Bichmann, W.: Primary health care: on measuring participation. Soc. Sci. Med. 26(9), 931-940 (1988)

28. Krogstad, D.J., Ruebush, T.K.: Community participation in the control of tropical diseases. Acta Trop. 61, 77-78 (1996)

29. Blood, R.: How blogging software reshapes the online community. Commun. ACM 47(12), 53-55 (2004)

30. Lindskog, H.: Smart communities initiatives. Presented at the Proceedings of the 3rd ISOneWorld Conference, pp. 14-16 (2004)

31. Basu, A., Virick, M.: Learning from experience: Novice and serial immigrant entrepreneurs in Silicon Valley. Presented at the 2013 Suzhou-Silicon Valley-Beijing International Innovation Conference (SIIC), pp. 40-52 (2013) 